\title{
TOSINKONNAST LÄTI LAENUST, MIS ENAMASTI POLE SEDA
}

\author{
ENN ERNITS
}

$\mathrm{H}$ iljuti arvustas läti ja soome keelest tõlkijana tuntud Kalev Kalkun (2012) Eesti Keele Instituudi leksikograafi Inge Käsi koostatud „Vanapärase Võru murde sõnaraamatut", kus tuuakse muu hulgas näiteid ka võimalikest vene, saksa ja läti laenudest. Vaadeldavas sõnaraamatus pole oma- ja laensõnu eristatud, seega on arvustaja laenuallika omapäi välja otsinud. Tavaliselt pole kombeks arvustust arvustada, aga et on eksimusi, siis ei saa mitte vaiki olla. Lisaks loodab siinkirjutaja kirjutisega veidi täiendada lõunaeesti sõnade päritolu ja keelekontaktide uurimist.

K. Kalkuni esitatud vähesed vene (arvult viis) ja saksa päritolu sõnade näited (kolm) on õiged, ent vastuväiteid kutsub esile enamik läti laensõnu. Paraku näib arvustaja olevat usaldanud ainult oma vaistu, mispuhul vaid mõni etümoloogia on läinud ka täkke. Tegelikult on arvustuses läti laenude pähe toodud tosin kagueesti keelenäidet erinevat päritolu. Kõigepealt leidub nende seas mitu omasõna. Üks neist on Eestis palju laiemalt tuntud kostum ( $m$ )a 'üles sulama, pehmenema' (VVMS: 250), kostma 'sulatama' ja kostutama 'sulatama, niisutama' (vt VMS I: 284). Sellel tüvel on vasteid teisteski läänemeresoome keeltes, nagu sm kostua, krj koštua, vps kostuda 'sulada', mistõttu kindlasti on tegemist läänemeresoome sõnaga (EEW III: 967). Järelikult saab sarnasus läti lekseemiga kust 'sulama' olla vaid juhuslikku laadi.

Sõnu klymba' 'lonkur' (VVMS: 232) ja lt klibs 'lonkav', millel on põhimõtteliselt sama tähendus, ei saa omavahel ühendada, sest tõsiseid probleeme tuleks $m$-hääliku selgitamisega. Lt klibs ongi laenatud võru keelepruuki kujul kliba (Vaba 1997: 90). Lekseemiga klymba kuulub kahtlemata kokku klympa$m a$ 'lonkama', millega on üsna sarnased üle Eesti eri paigust registreeritud kitsama või laiema levikuga klimpama, limpama, limpima, lompama, lumpama, lömpama, lümpäme tähenduses 'lonkama'. Eeldades, et 'lonkama' tähendas 'longates käima', tohiks siinkohal kõrvutada ka $m p$-ühenditega sõnu, mis tähendavad 'kuidagi eriliselt käima, lonkima, vantsima', nagu lampima, lämpama, lämpima 'käima'. Siinpuhul väärivad tähelepanu ka häälikuühendit -mps- sisaldavad klõmpsima, klömpsama, klömpsima, lempsama, limps(i)ma, lömpsima 'lonkama' ning lampsma 'käima' (leviku kohta vt VMS I: 242, 245, $404,425,440,470,491,497,502)$. Niisiis näivad kõik nimetatud $(k) l \mathrm{~V} m p(s) \mathrm{V}$ -

\footnotetext{
${ }^{1}$ Selles kirjutises kasutatakse teadusliku transkriptsiooni asemel lihtsuse mõttes võru kirjaviisi.
} 
tüvega sõnad kuuluvat deskriptiivsete ehk viimasel ajal soome teadlaste terminieelistuse kohaselt ekspressiivsete kilda. ${ }^{2}$ Tegelikult pole see üheselt nõnda.

Asja komplitseerib tõik, et vähemalt sõna limpama peetakse, tõsi küll kahtlemisi, laensõnaks. Eesti sõnal on täielik vaste soome keeles kujul limpata 'longata'. Nende lähteks peetakse küsimärgiliselt germaani keeli, vrd omavahel suguluses olevaid samatähenduslikke sõnu ingl limp, küsks limp$f e n$, samuti lampen 'alla rippuma'; eesti $k l$-algusega kuju on seejuures peetud deskriptiivseks (EEW IV: 1314-1315; SSA II: 77-78; ChDE: 598). Kui saksa lekseemis arvestada veel tüvemuutustega limpf-, lampf-, lumpf- (MW I: 1000), siis saakski põhjendada suurema osa eesti $(k) l \mathrm{~V} m p(s) \mathrm{V}$-tüveliste sõnade tekke. Alo Raun peab sõna lompama deskriptiivseks (EET: 78). Sõna lämpama 'lonkama väljapoole pööratud jalaga' kõrvutatakse teiste sarnaste läänemeresoome sõnadega, nt sm lämmytä, vps lämbuda 'painduda', mida peetakse samuti deskriptiivseks (EEW V: 1444-1445; SSA 2: 124). Häälikuline vastavus pole päris täielik (*mpp $\sim{ }^{*} m p$ ). Sõnasisene $-a$ - on kõigil eespool esita- tud juhtudel tuletusliide.

Ekspressiivsõnade uurimine on andnud sageli üsna vastuolulisi tulemusi. Üldiselt võimaldab ühe või teise sõna ekspressiivseks tunnistamine kergeid, ent puhuti isegi liiga kergeid lahendusi, mis võivad, aga ei tarvitse tõde kajastada. Käsitletavas sõnakimbus, mis väljendab kehalist puuet, sisaldab kaheldamatult ka ekspressiivset alget. Ühelt poolt võib oletada, et tegu on algse germaani laenuga, mis on eri paigus, eri aegadel ja eri põhjustel andnud erineva struktuuriga sõnu. Lisaks on oma osa etendanud ka mõiste kalduvus ekspressiivsusele. Teisalt pole välistatud, et afektile ei tugine ka germaani sõna, mida seostatakse tähendusega 'kõver, längus' (SSA 2: 78).

Onomatopoeetiline näib olevat ka mäürämmä 'mörisema' (VVMS: 443), vrd ka Lüganuse mäurama 'möirgama'. Neile lähedaste tähendustega on maurama, meurama, mourama, mõurama, möurama (VMS II: 20, 27, 34, 53, 63). Omal ajal pidas taani keeleteadlane Vilhelm Thomsen läti sõna maurot 'möirgama (veiste kohta)' läänemeresoome laenuks (lv mour, ee mõurama samas tähenduses), ent hiljem leiti sama tüvega lekseem ka leedu keelest ja mõlemale indoeuroopa päritolu (LDW II: 570; LEV: 573). Tüvi maur esineb kujul mauruta 'näuguda (kiimase kassi kohta); hädaldada; haliseda; nuruda; manguda' ka soome keeles. ${ }^{3}$ Selle onomatopoeetilises päritolus pole kaheldud, ent seda on ekslikult ühendatud eesti sõnaga maaruma 'manguma, nuruda', mis on tegelikult lähtunud mustlaskeelest (SSA 2: 155; vt Ariste 2010: 231 jj).4

K. Kalkun kõrvutas kolm rä̈̈-algulist Kagu-Eesti sõna (räüs, rä̈̈ttmä, räüstämä) läti sõnaga raustīt 'tõmbama, tirima'. Ilmselt on nende lekseemide algupära erinev või üksnes osaliselt kattuv. Lõunaeesti sõna rä̈̈s ( $s$ hääldub poolpikalt) 'rahe' (VVMS: 640) ekspressiivset päritolu ei peeta kindlaks, kuid sobivaid vasteid sugulas- ega muudest keeltest pole ka leitud (vt EEW VIII: 2593). Seetõttu tuleb arvata, et tegu on tõenäoliselt genuiinse lekseemiga.

Samuti on seni jäänud tulemusteta setu räütmä 'maha tallama; sasima' (VVMS: 641) teiste keeltega kõrvutamine. Ehituselt sarnased sõnad esinevad

\footnotetext{
${ }^{2}$ Vt näiteks Forsberg 2010: $5 \mathrm{jj}$.

${ }^{3}$ SES 1: 845 esitab osaliselt teised tähendused 'koriseda (kõhu kohta); nuruda; manguda, lunida'. Tähenduses 'manguda' esineb ka näiteks sm naukua 'näuguda jt' (SES 1: 966).

${ }^{4}$ SSA peab alusetult (tõsi küll, kahtlemisi) läti sõna ka läänemeresoome laenuks.
} 
ka Põhja- ja Kirde-Eestis ning nende tähendusi 'poolpehmeks keetma' ja 'kupatama' saab samuti eelmistega ühendada (vt VMS II: 357 räitama alt). Eri lugu on tähendusega 'hulkuma' (Lüganuse). Paremate ideede puudumisel tuleks siiski oletada, et tegu on genuiinse, võib-olla ekspressiivse sõnatüvega.

Vastseliina kandi räüstämä 'rüüstama' (VVMS: 641) pole samuti üksnes võru keele sõna, vaid on tegelikult idaeestilise levikuga, ulatudes Jõhvist Vastseliinani (VMS II: 357 räistama all). Selle päritolu pole seni vist üldse uuritud. Siinpuhul võib eeldada, et 'rüüstama' ja 'rebima' kuuluvad samasse tähendusteringi, nagu näiteks sm riistää tähendab nii 'rebida' kui ka 'röövida' (SES 2: 58). Kui oletada tähenduse edasiarengut 'rebima' $\rightarrow$ 'rüüstama' alles pärast laenamist, siis on võimalik kõrvutada sõna räüstämä K. Kalkuni pakutud läti vastega raustīt 'rebima; tirima; tõmblema; kisklema', mis koos leedu sõnaga raústyti 'rebima' kujutab endast korduvat tegevust väljendavat tuletist ehk iteratiivi (vrd lt raut 'kiskuma, tõmbama' ja ld ráuti 'üles tõmbama; välja rebima', asjaomane sõnatüvi kuulub algindoeuroopa varamusse, vt LEV: 743; LEW II: 708-709). Vastavust lt $a u \sim$ ee ä̈̈ on seni täheldatud vaid ühes ekspressiivses läti laenverbis aurama äürämä 'valju häälega nutma; röökima; möirgama; möögima' (vt Vaba 1997: 67). Päris tavaline pole ka järgsilbi lt $\bar{\imath} \sim$ ee $a / \ddot{a}$ vastavus, kuid seda siiski esineb, vrd Räpina labatama 'lunastama, ostma' lt labit 'lepitama; paitama; ülistama' (tähendusnihe vajaks küll selgitamist), lei soetama 'saatma' lt sutīt 'saatma' ja mõnel küsimärgiga juhul (Vaba 1997: 115, 360). Nagu käsitletust selgub, kahandab mitu mööndust laenuetümoloogia usutavust, kuid päris võimatu see ei ole.

Teisalt on sõnal rä̈̈stämä üsna sarnased vasted sugulaskeeltes, nagu ee rü̈istama, sm ryöstää 'röövida, riisuda; rüüstata', raastaa 'puruks rebida; riivida; tirida', krj (lüüdi) ruastada 'rebida; kraapida; riisuda', vps rastta räss$t a \sim$ röstta 'rebida, kitkuda; riisuda' jt. Oletatakse, et tegu on ekspressiivverbidega, mille esisilbi erinevate vokaalidega variantide vahel valitsevat mingi hämar seos (EEW VIII: 2637; SSA 3: 34-35, 75, 122; SVJ: 491). Sel juhul pole ju võimatu, et ka räüstämä on ekspressiivset algupära. Uuritav verb on ehituselt sarnane Urvaste, Rõuge, Põlva ja Lutsi sõnaga räüssäm $(m) \ddot{a}$ 'maha tallama' ning viimati mainitud sõna tähendus eespool käsitletud räütmä-sõnaga. Kas sellest ka midagi olulist tuletada saaks, ei julge veel öelda.

Vene keelest pärinevad, nagu Mari Must on kindlaks teinud, setu kryyn$k a$, krynka 'savist piimapott' (VVMS: 257), vrd vn крынка 'savipott; potitäis (piima)', puustusõmaa 'puustus' (VVMS: 579), vrd vn nycmous 'tühi, harimata maa, kõnnumaa' ning seräknäq 'tuletikud' (VVMS: 667), vrd vn серенка, серянка sõnast серная спичка 'väävlitikk' (Must 2000: 148, 318-319). Juhtumisi on lt sêrkocinšs 'tuletikk' mõnevõrra sarnane seetõttu, et lt sērs 'väävel' on laenatud kas idaslaavi keeltest või on mõlemal juhul tegu algse ühise indoeuroopa tüvega (LEV: 807). 5

Huvi pakub üsna laialdase levikuga, nimelt Tartu- (ainult Võnnu murrakust), Võru-, Setu- ja Lutsimaalt kirja pandud salitsa(m)ma salitsõmma 'nöörile ajama, lükkima' (VVMS: 655; VMS II: 382), mille päritolu oli seni peetud ebaselgeks (vt EEW VIII: 2684; Koponen 1998: 163). K. Kalkun seostas asjaomase lekseemi läti sõnaga salikt 'kokku panema, kokku laduma', mis esineb ka kujul salicināt (LDW III: 671). Mõlemad läti sõnad koosnevad prefik-

${ }^{5}$ Lt kociņš (< koks 'puu') on LDW II: 340 registreerinud vaid tähendustes 'tugev inimene', 'lihtsameelne inimene' ja 'mesipuu'. 
sist $s a$ - 'kokku' ja verbidest licināt või likt (teatud vormides $k>c$ ) põhitähenduses 'panema'; esimene neist esineb tänapäeval vaid koos eesliitega, nt atlicināt 'kõrvale panema, tagavaraks panema' (LDW II: 465, 467). Läti sõna lik- peetakse indoeuroopa algupäraga tüveks (LEV: 535). Käsitletava lõunaeesti sõna pööramisel jääb osas vormidest tse-/tsõ-osis seaduspäraselt liitmata. Seega on pärast laenamist hakatud uuritavat sõna pöörama analoogiliselt teiste, genuiinset tse-liidet sisaldavate sõnadega, nagu valitsõma, manitsõma (VES: 513, 597). Teisalt on Võru- ja Setumaalt ning isegi Rapla kandist registreeritud salima sal'ma 'lükkima' (VMS II: 382). Sel juhul on tse-d peetud liitena ilmselt ebaoluliseks. Kuusalu, Kadrina, Kodavere sal'm 'ketilüli, aas' ja salitsema 'kaapima' vajavad eraldi uurimist. Lisatagu, et K. Kalkuni esitatud sõnade hulgas peetakse kahtlemata läti laenuks üldeestiliseks saanud sõna nuumama (VVMS: 467; vt Vaba 1997: 143-144).

Omaette pähkel on Lõuna-Eestis laiema levikuga virges 'vagu' (VVMS: 865; vt ka VMS II: 689). See ei seostu otseselt läti sõnaga virkne 'rida, rodu' - milles $k<* t$ - erinevate lõpuosade poolest. Julius Mägiste on kõrvutanud tema enda arvates läänemeresoome päritoluga sõna virges eesti sõnadega virg : virge 'laineline mullakuhjatis rannal', vire : vire 'veejoom, tuulest tekkinud veeviir' (vrd sm vire : vireen virkeen 'väike laine') ning viimaks küsimärgiliselt sõnaga virendama virvendama (EEW XII: 3873, 3875). Eino Koponen (1998: 62-63, 195-196) ühendas virges-sõna põhjaeesti sõnaga viirg, pidades lähteks deskriptiivse algupäraga tüve *vir-. Ekspressiivsõnaks peab soome sõna vire viri ka SSA (3: 456). Lisaks on läänemeresoome keeltes tähendusega 'miski perioodiliselt või teatud vahemaa järel korduv' sõnu veelgi nagu näiteks vdj virka 'rida, rodu; helmevöö'.

Sõna viirg jt on oletamisi peetud ka balti laenudeks, ent segavaks asjaoluks on saanud leedu tähendusvastete puudumine. Seevastu kõhklusi läänemeresoome omasõnaks pidamiseks lisavad häälikuliselt ja tähenduselt sarnased indoeuroopa (läti ja slaavi) sõnad, nagu lt verdze (<*verge) 'suur hunnik; pikk rivi', virgele 'toaehteks niidile lükitud õletükid ja kirjud paberitükid; õlest kett' (vrd lt vert 'lükkima'), vn верениц̧ 'pikk rivi' jt. Mainitud lekseemid lähtuvad indoeuroopa tüvest *ŭer 'pöörama' (LDW IV: 605). Kahjuks pole eesti keeles omasõna ja laensõna dilemmat seni veel õnnestunud lahendada (lähemalt vt Ernits 1999: 13 jj).

Mida võiks öelda kokkuvõtteks? Enamik K. Kalkuni eeldatud läti laensõnu tegelikult seda pole. Käsitletute seas on nii omasõnu kui ka vene laene. Suur osa sõnu on ekspressiivleksika tunnustega, kuid samal ajal võib mõnele neist leida vasteid balti keeltest. Tundub, et mõni esialgu laenatud sõna võis eri paigus, aegadel ja põhjustel anda erinevaid variante, hakates sarnanema ekspressiivsõnadega. Praegu on konkreetsete teadmiste osas veel palju ebaselget, mida keelekontaktide uurijatel tuleks eriti lõunaeesti murrete põhjal kui ka laiemaltki selgitada.

\section{Tekstis kasutatud lühendeid}

K e e l e d: ee = eesti; ingl = inglise; $\mathbf{k r j}=$ karjala; küsks = keskülemsaksa; $\mathbf{l d}=$ leedu; lei = leivu; lt = läti; lv = liivi; $\mathbf{s m ~ = ~ s o o m e ; ~ v d j ~ = ~ v a d j a ; ~} \mathbf{v n}=$ vene; $\mathbf{v p s ~ = ~}$ vepsa. 


\section{Kirjandus}

A r is te, Paul 2010. Sõnalaenulõbu. (Eesti mõttelugu 93.) Koost Peeter Olesk. Tartu: Ilmamaa.

ChDE $=$ Chambers Dictionary of Etymology. Toim Robert K. Barnhart. Chambers, 2008.

$\mathrm{EET}=$ Alo Raun, Eesti keele etümoloogiline teatmik. Rooma-Toronto: Maarjamaa, 1982.

EEW = Julius Mägiste, Estnisches etymologisches Wörterbuch I-XII. Helsinki: Finnisch-Ugrische Gesellschaft, 1982-1983.

E r n it s, Enn 1999. Setu sõna siit, kreevini lause seal. - Emakeele Seltsi aastaraamat 43. Peatoim Mati Erelt, tegevtoim Tõnu Tender. Tartu: Eesti Teaduste Akadeemia Emakeele Selts, lk 13-21.

Forsberg (Kulonen), Ulla-Maija 2010. Expressive Vocabulary in the Early Phases of Finno-Ugrian. - Congressus XI Internationalis Fenno-Ugristarum. Piliscsaba 9.-14. VIII. 2010. Pars I. Orationes plenariae. Piliscsaba, lk 5-19.

K a 1 k u n, Kalev 2012. Noppeid võru keelest. - Keel ja Kirjandus, nr 1, lk 66-67.

K o p o n e n, Eino 1998. Eteläviron murteen sanaston alkuperä: Itämerensuomalaista etymologiaa. (Suomalais-Ugrilaisen Seuran toimituksia 230.) Helsinki: Suomalais-Ugrilainen Seura.

LDW = K. Mülenbacha Latviešu valodas vārdnīca I-IV. Rediǵēejis, papildinājis, nobeidzis J. Endzelīns. Rīgā: Kultūras fonda izdevums, 1929-1932.

LEV = Konstantīns Karulis, Latviešu etimoloǵijas vārdnīca. [Rīga]: Avots, 2001.

LEW = Ernst Fraenkel, Litauisches etymologisches Wörterbuch II. HeidelbergGöttingen: Carl Winter Universitätsverlag - Vandenhoeck \& Ruprecht, 1965.

M u s t, Mari 2000. Vene laensõnad eesti murretes. Tallinn: Eesti Keele Sihtasutus.

MW = Wilhelm Müller, Mittelhochdeutsches Wörterbuch mit Benutzung des Nachlasses von Wilhelm Friedrich Benecke 1. Leipzig: S. Hirzel, 1854.

SES = Soome-eesti suursõnaraamat. Suomi-viro suursanakirja 1-2. Tallinn-Helsinki: Eesti Keele Sihtasutus - Kotimaisten kielten tutkimuskeskus, 2003.

SSA = Suomen sanojen alkuperä. Etymologinen sanakirja 1-3. (Suomalaisen Kirjallisuuden Seuran toimituksia 556. Kotimaisten kielten tutkimuskeskuksen julkaisuja 62.) Helsinki: Suomalaisen Kirjallisuuden Seura, Kotimaisten kielten tutkimuskeskus, 1992-2000.

SVJ = M. 3 ай це в а, M. Му л о нен, Словарь вепсского языка. Денинград: Наука, 1972.

V a b a, Lembit 1997. Uurimusi läti-eesti keelesuhetest. Eesti Keele Instituut, Tampereen yliopiston suomen kielen ja yleisen kielitieteen laitos. Tallinn-Tampere.

VES = Võro-eesti synaraamat. Kokko pandnuq Jüvä Sullõv. (Võro Instituudi toimõndusõq 12). Tarto-Võro: Võro Instituut', 2002.

VMS = Väike murdesõnastik I-II. Toim Valdek Pall. Tallinn: Valgus, 1982-1989. VVMS = Vanapärase Võru murde sõnaraamat. Rõuge, Vastseliina, Setu. Koost Inge Käsi. Toim Helmi Neetar. Tallinn: Eesti Keele Sihtasutus, 2011. 